\title{
Hyperthyroidism in a complete molar pregnancy with a mature cystic ovarian teratoma
}

\author{
Bryce C. Simes ${ }^{1 *}$ D, Alozie A. Mbanaso ${ }^{1}$, Carlos A. Zapata ${ }^{2}$ and Chukwuma M. Okoroji ${ }^{3}$
}

\begin{abstract}
Background: The hallmark of gestational trophoblastic disease is the production of human chorionic gonadotropin (hCG) due to the hyperproliferation of extraembryonic trophoblast cells. Previous studies show hCG has thyrotropic action due to its structural similarity with thyroid stimulating hormone (TSH) molecules. Germ cell tumors represent $15-20 \%$ of all ovarian tumors and can be malignant or benign.

Case presentation: We present a case of a 53-year old African American female with a history of hyperthyroidism secondary to a complete hydatidiform mole and an associated finding of a mature cystic ovarian teratoma. She presented with nausea, vomiting, nervousness, weight gain, abdominal pain and a b-hCG of greater than $450,000 \mathrm{mlU} / \mathrm{mL}$. A total abdominal hysterectomy with bilateral salpingo-oophorectomy was performed and curative for her symptoms. Lung nodules were noted with slight increases in b-hCG levels in the months following the surgery. Propranolol and methimazole were used to treat the acute hyperthyroid symptoms.

Conclusion: This case presents the rare occurrence of a complete hydatidiform mole causing hyperthyroidism and an associated finding of a mature cystic teratoma. It also highlights the importance of monitoring b-hCG levels following a complete molar pregnancy due to an increased risk of choriocarcinoma.
\end{abstract}

Keywords: Hydatidiform mole, Complete molar pregnancy, Hyperthyroidism, Mature cystic ovarian teratoma, Beta-human chorionic gonadotropin (b-hCG), Beta-carboxy-terminal peptide (b-CTP)

\section{Background}

Thyroid stimulating hormone (TSH), follicle stimulating hormone (FSH), luteinizing hormone ( $\mathrm{LH})$ and human chorionic gonadotropin (hCG) are a family of heterodimeric glycoprotein hormones composed of an alpha and beta subunit. All members of the family share a common alpha-subunit and have a different functional beta-subunit $[1,2]$. Studies have shown that LH and hCG compete with TSH to bind to TSH receptors. The beta subunits of both LH and hCG share an $85 \%$ sequence identity, but the presence of beta-carboxy terminal peptide (b-CTP), a 31-amino acid extension on the beta-subunit, is unique to hCG [3]. Both hormones have demonstrated thyrotropic action on the thyroid gland [4]. LH is a more potent stimulator of the TSH receptor, but when the b-CTP is

\footnotetext{
*Correspondence: simesbc@acom.edu

'Alabama College of Osteopathic Medicine, 445 Health Sciences Blvd,

Dothan, AL 36303, USA

Full list of author information is available at the end of the article
}

removed from a hCG molecule, the stimulatory effect on TSH receptors is identical. It is likely that b-CTP's role is to protect women from thyrotoxicosis during normal pregnancy when b-hCG is produced in large amounts by the placenta [3].

Pregnancy causes significant changes to the thyroid gland that are reversible. The hypothalamicpituitary-thyroid feedback system is altered by the thyrotropic effect of b-hCG. A slight suppression in TSH and increase in $\mathrm{T}_{4}$ levels are seen in normal pregnancy. Hyperemesis gravidarum is a common presentation during the first trimester of pregnancy. It is a multifactorial disease, but hCG production and its thyrotropic action likely play a significant role. $70 \%$ of women with hyperemesis gravidarum have abnormal thyroid function. The hyperthyroid state reverses by the second trimester in almost all women during a normal pregnancy $[3,5]$. Women with complete molar pregnancies also experience worse nausea and vomiting than those with normal 
pregnancies due to the significantly elevated hCG production [6].

Gestational trophoblastic disease (GTD) is a group of tumors characterized by the production of hCG due to the hyperproliferation of extraembryonic trophoblast cells. They are either hydatidiform moles or trophoblastic neoplasms [7]. Maternal age is the most significant risk factor for the development of a hydatidiform mole among all regions and ethnicities. Data shows that the there is higher risk in those above the age of 35 and an additional 10-fold increased risk in those above the age of 40 [8]. Gestational trophoblastic neoplasia (GTN) is a group of tumors with the possibility of local invasion and metastases. These include choriocarcinoma, placental site trophoblastic tumors and epithelioid trophoblastic tumors. Hydatidiform moles can sometimes be clinically considered GTN even though it is not an actual neoplasm due to its ability to invade locally and metastasize [9].

Germ cell tumors represent $15-20 \%$ of all ovarian tumors. Most (95\%) of these tumors are benign cystic teratomas but $5 \%$ are malignant. Mature cystic teratoma, choriocarcinoma and dysgerminoma are examples of germ cell tumors that can secrete hCG. Surgical management and chemotherapy are the main treatment options for those with germ cell ovarian tumors [10].

\section{Case presentation}

A 53-year-old African-American female with a history of uterine fibroids presented with a two-month history of nausea, vomiting, nervousness, weight gain and left lower quadrant abdominal pain. Weeks prior, she also went to the emergency department for similar symptoms where an abdominal computerized tomography (CT) scan showed an enlarged uterus along with fibroids, a hemorrhagic cyst of the right ovary and a teratoma of the left ovary (Fig. 1) (Fig. 2) (Fig. 3). Regions of calcification were present measuring a maximum of $1.8 \mathrm{~cm}$.

Physical exam revealed a soft, non-distended abdomen with pain upon deep palpation localized to the left lower quadrant. The thyroid gland was palpable, with an estimated weight of thirty to forty grams. It was nodular and nontender. The Pemberton sign checking for venous obstruction due to a goiter was negative. Tachycardia was present with a normal rhythm. S1 and S2 were normal with no S3, S4, gallops or murmurs detected. Initial labs revealed a mild normocytic anemia, a low TSH level and slightly elevated transaminases (Table 1).

An endocrinology consultation was placed due to the abnormal TSH levels indicating hyperthyroidism. Baseline thyroid testing showed a TSH $0.04 \mathrm{mIU} / \mathrm{L}$ (ref. range: $0.340-5.600 \mathrm{mIU} / \mathrm{L}$ ), free T4 level of $4.03 \mathrm{ng} / \mathrm{dL}$ (ref. range: $0.61-1.12 \mathrm{ng} / \mathrm{dL}$ ) and total $\mathrm{T} 3$ of $451 \mathrm{ng} / \mathrm{dL}$ (ref. range: $60-181 \mathrm{ng} / \mathrm{dL}$ ). A baseline thyroid ultrasound was

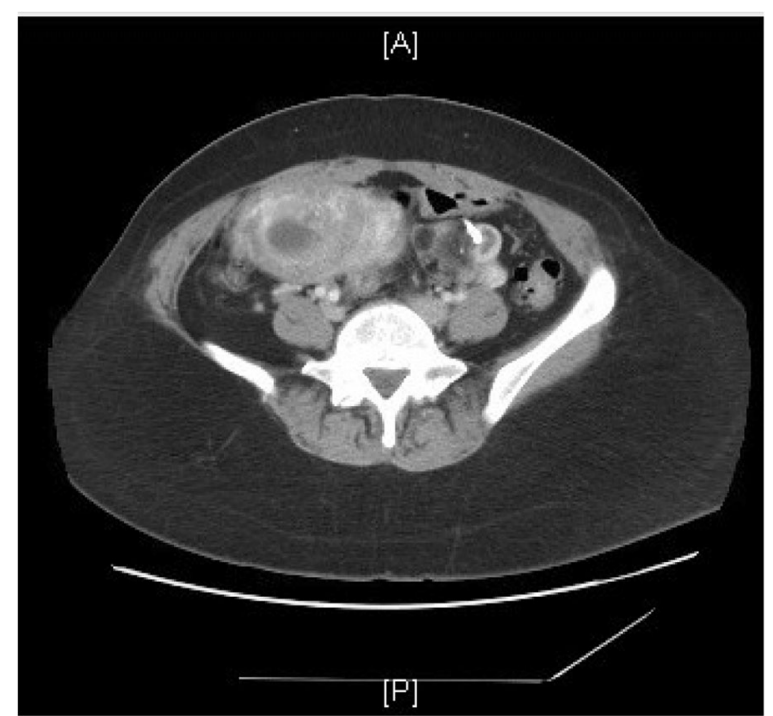

Fig. 1 Axial view - Abdominal CT scan showing a left sided ovarian teratoma with calcification

also performed that showed a bilaterally enlarged thyroid gland, consistent with a goiter. Both lobes were heterogeneous. Multiple cystic and complex nodules were seen bilaterally. The largest of these measured $1.5 \times 1.1 \times$ $1.6 \mathrm{~cm}$ on the left lobe. There were small encapsulated nodules seen on each lobe. These findings were consistent with a multinodular goiter. The hyperthyroid symptoms improved after the administration of antithyroid medications: propranolol and methimazole.

Beta-hCG intact was measured twice, showing a value greater than $450,000 \mathrm{mIU} / \mathrm{mL}$. Because of the combination of ovarian and uterine pathology present, the

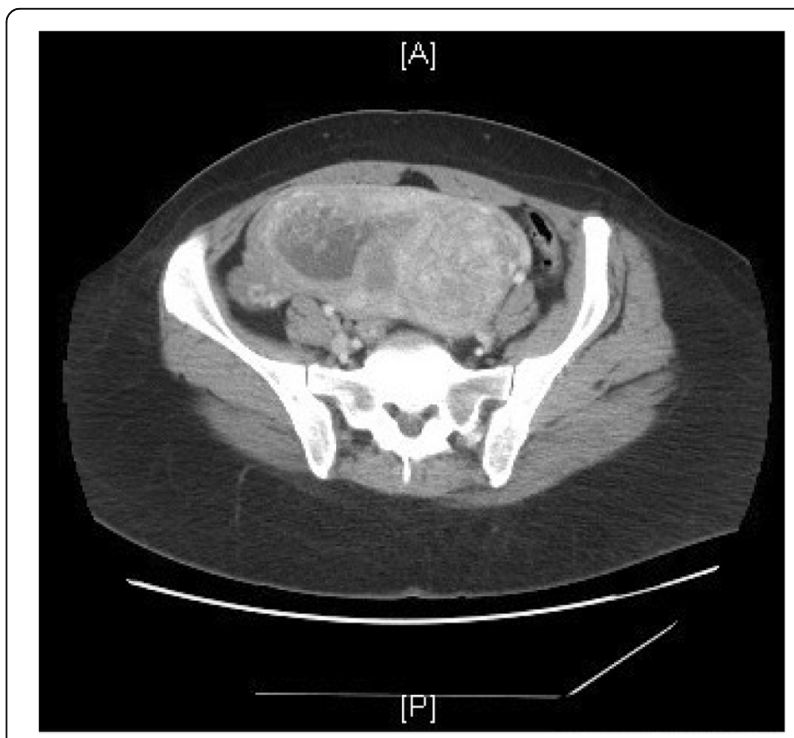

Fig. 2 Axial view - Abdominal CT scan with an enlarged uterus due to a complete molar pregnancy 


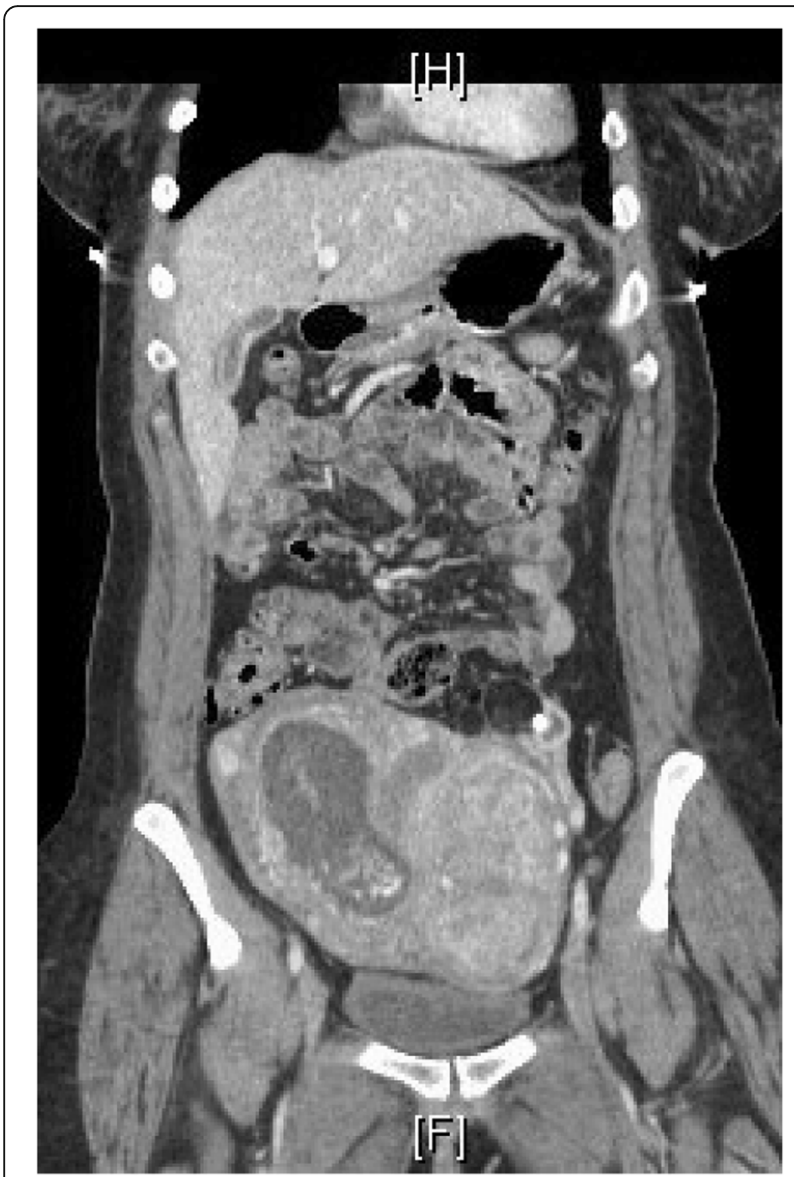

Fig. 3 Coronal view - Abdominal CT scan showing a left sided ovarian teratoma and complete hydatidiform mole

Table 1 Initial laboratory values at admission

\begin{tabular}{ll}
\hline WBC & $10,300 / \mathrm{mm}^{3}$ \\
Hemoglobin & $10.7 \mathrm{gm} / \mathrm{dL}$ \\
Hematocrit & $31.3 \%$ \\
Platelets & $236,000 / \mathrm{mm}^{3}$ \\
Sodium & $134 \mathrm{mmol} / \mathrm{L}$ \\
Potassium & $3.7 \mathrm{mmol} / \mathrm{L}$ \\
BUN & $9 \mathrm{mg} / \mathrm{dL}$ \\
Creatinine & $0.5 \mathrm{mg} / \mathrm{dL}$ \\
Glucose & $105 \mathrm{mg} / \mathrm{dL}$ \\
AST & $89 \mathrm{units} / \mathrm{L}$ \\
ALT & $59 \mathrm{units} / \mathrm{L}$ \\
Alkaline Phosphatase & $126 \mathrm{units} / \mathrm{L}$ \\
PT & 11.7 \\
INR & 1.1 \\
PTT & 27.4 \\
Blood Acetone & Negative \\
\hline
\end{tabular}

patient was recommended for a total abdominal hysterectomy with bilateral salpingo-oophorectomy. Following surgery, b-hCG levels dropped from greater than $450,000 \mathrm{mIU} / \mathrm{mL}$ to $200,000 \mathrm{mIU} / \mathrm{mL}$ and continued to decrease over the course of the hospital stay (Fig. 4). The methimazole and propranolol doses were also titrated as the hyperthyroidism became less symptomatic. Tissue diagnosis by the pathology laboratory confirmed the ovarian teratoma (Fig. 5). Sections of the myometrial wall containing massive hydropic chorionic villi with the presence of intravillous vascular cistern were noted along with excess trophoblastic proliferation (Fig. 6). This, along with the extremely high b-hCG levels, was consistent with the presentation of a complete hydatidiform mole.

After discharge, the patient underwent serial b-hCG measurements until the levels were undetectable to monitor the potential development of GTN. Post-surgical management also included methotrexate for chemotherapy. During the course of chemotherapy, lung nodules were found on a subsequent CT scan along with a slight upswing in b-hCG. However, as more time passed, the levels of b-hCG were eventually undetectable, and there was no subsequent choriocarcinoma post complete molar pregnancy.

Thyroid hormone levels were also monitored after discharge from the hospital and low-dose methimazole was continued. There was a significant improvement in the thyroid hormone levels 1 month following the surgery: TSH $0.5 \mathrm{mIU} / \mathrm{L}$, free $\mathrm{T} 40.77 \mathrm{ng} / \mathrm{dL}$ and free $\mathrm{T} 3$ $2.26 \mathrm{pg} / \mathrm{mL}$ (ref. range: $2.3-4.2 \mathrm{pg} / \mathrm{mL}$ ). TSH levels were continuously monitored for 12 months following the surgery and remained normal. A year after the surgery, the patient also sought treatment at the Mayo Clinic, who performed a fine needle aspiration biopsy (FNAB) of a thyroid nodule. The patient reported the FNAB results as negative and the methimazole was then discontinued.

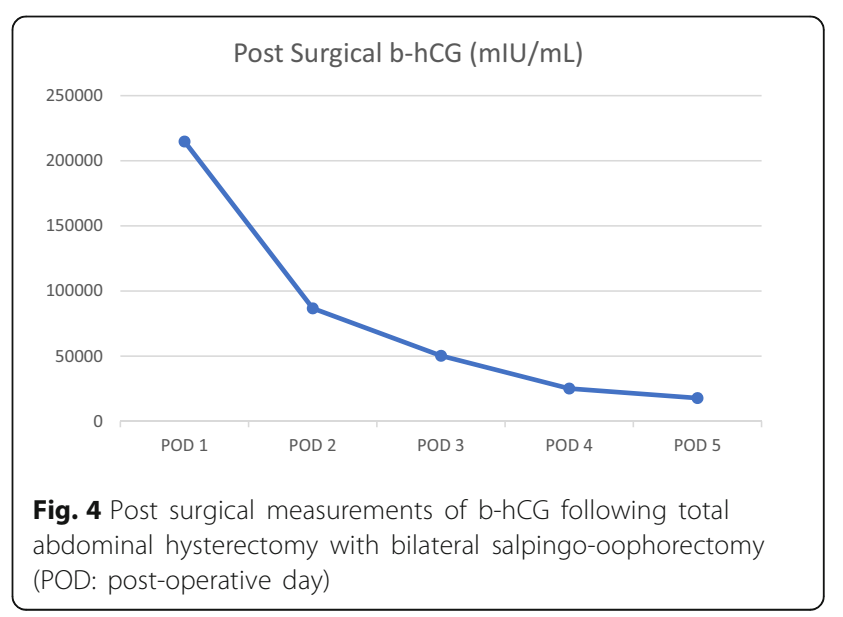




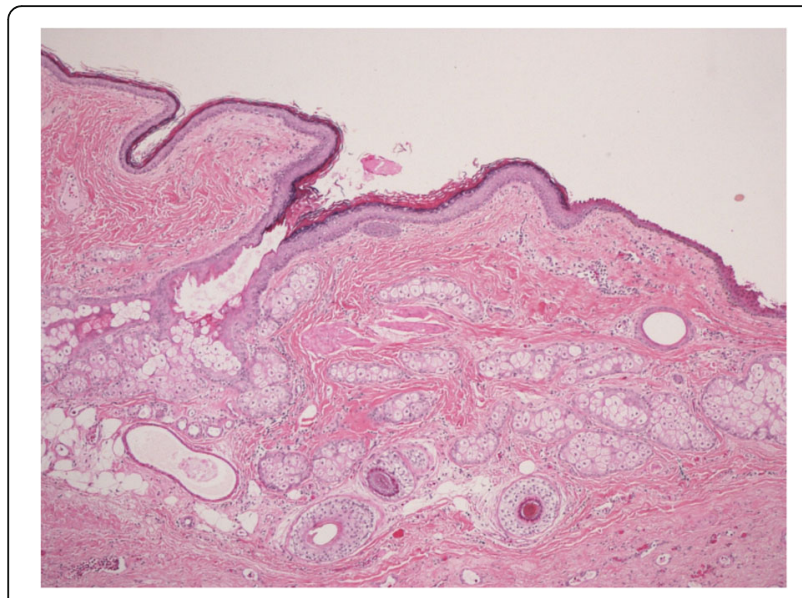

Fig. 5 Left sided ovarian teratoma demonstrating cystic cavities lined by mature epidermis

\section{Discussion and conclusions}

The association between a molar pregnancy and hyperthyroidism was discovered by Tisne, Barzelatto and Stevenson in 1955 [11]. This case presents the rare occurrence of a complete hydatidiform mole causing hyperthyroidism and an associated finding of a mature cystic teratoma. It also serves as a reminder that in rare occasions, supraphysiologic levels of b-hCG can have a thyrotropic effect due to its structural similarity to TSH's molecular structure. Antithyroid medications should be initiated for the management of hyperthyroid symptoms until surgical removal of the source of the b-hCG secretion can be completed.

Following the resolution of gestational trophoblastic diseases, such as a hydatidiform mole, management should continue to evaluate for the development of gestational trophoblastic neoplasia. As many of $20 \%$ of

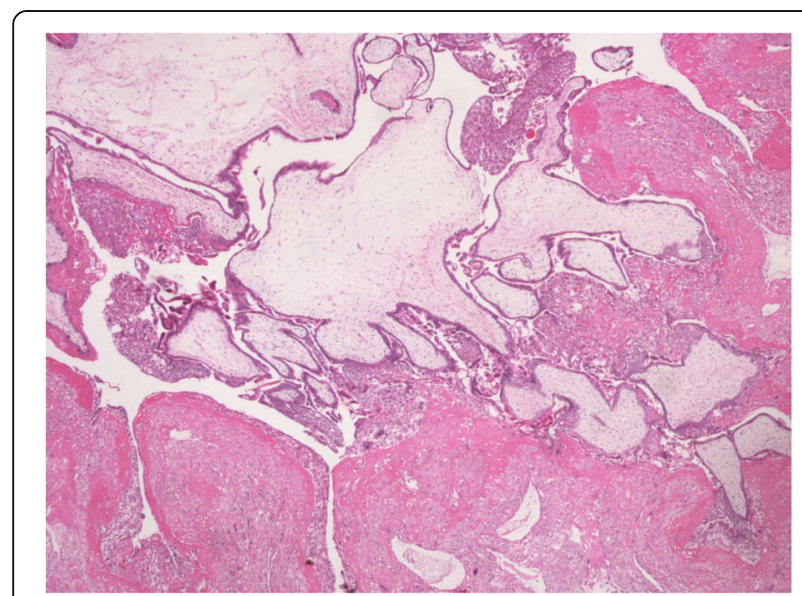

Fig. 6 Complete molar pregnancy demonstrating massive hydropic chorionic villi, the presence of intravillous vascular cistern and excessive trophoblastic proliferation complete hydatidiform moles develop GTN. Serum b-hCG should be measured weekly until levels are undetectable within 6 months. Once undetectable, serial b-hCG measurements should continue for three more weeks to confirm resolution. If the level remains undetectable, the timing of the b-hCG measurements should be switched to monthly for another three to 6 months. If the b-hCG remains elevated or unchanged, evaluation for metastatic disease should be initiated [12]. The most common location for GTN distal invasion include the lungs and vagina [13].

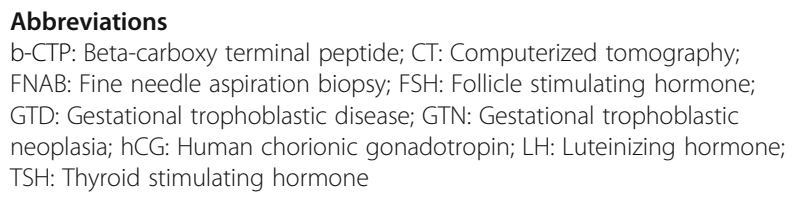
FNAB: Fine needle aspiration biopsy; FSH: Follicle stimulating hormone; GTD: Gestational trophoblastic disease; GTN: Gestational trophoblastic neoplasia; hCG: Human chorionic gonadotropin; LH: Luteinizing hormone; TSH: Thyroid stimulating hormone

\section{Availability of data and materials}

Data sharing is not applicable to this article as no datasets were generated or analyzed during the current study.

\section{Authors' contributions}

All authors have contributed to, read, and approved this manuscript. CAZ and $\mathrm{CMO}$ were directly involved in the endocrine and obstetrical management of this patient.

\section{Ethics approval and consent to participate}

The need for ethics approval was waived by the Alabama College of Osteopathic Medicine.

\section{Consent for publication}

The patient has provided their consent for the contents of this report to be published.

\section{Competing interests}

The authors declare that they have no competing interests.

\section{Publisher's Note}

Springer Nature remains neutral with regard to jurisdictional claims in published maps and institutional affiliations.

\section{Author details}

'Alabama College of Osteopathic Medicine, 445 Health Sciences Blvd, Dothan, AL 36303, USA. ${ }^{2}$ Northwest Florida Diagnostic Endocrinology Clinic, Tallahassee, FL, USA. ${ }^{3}$ Nature Coast Healthcare Center, Tallahassee, FL, USA.

Received: 20 July 2018 Accepted: 3 August 2018

Published online: 10 August 2018

\section{References}

1. Fares FA, Gruener N, Kraiem Z. The role of the asparagine-linked oligosaccharides of the alpha-subunit in human thyrotropin bioactivity. Endocrinology. 1996;137(2):555-60.

2. Cahoreau C, Klett D, Combarnous Y. Structure-function relationships of glycoprotein hormones and their subunits' ancestors. Front Endocrinol. 2015;6:26.

3. Carayon P, Lefort G, Nisula B. Interaction of human chorionic gonadotropin and human luteinizing hormone with human thyroid membranes. Endocrinology. 1980;106(6):1907-16.

4. Yoshimura M, Hershman JM. Thyrotropic action of human chorionic gonadotropin. Thyroid. 1995;5(5):425-34.

5. Goodwin TM. The role of chorionic gonadotropin in transient hyperthyroidism of hyperemesis gravidarum. J Clin Endocrinol Metab. 1992; 75(5):1333-7.

6. Bustos M, Venkataramanan R, Caritis S. Nausea and vomiting of pregnancy Whats new? Auton Neurosci. 2017;202:62-72. 
7. Bruce S, Sorosky J. Gestational Trophoblastic Disease. [Updated 2017 Dec 4]. In: StatPearls [Internet]. Treasure Island: StatPearls Publishing; 2018. Available from: https://www.ncbi.nlm.nih.gov/books/NBK470267/.

8. Bracken MB, Brinton LA, Hayashi K. Epidemiology of Hydatidiform mole and Choriocarcinoma. Epidemiol Rev. 1984;6(1):52-75.

9. Shih I-M. Gestational trophoblastic neoplasia-pathogenesis and potential therapeutic targets. Lancet Oncol. 2007;8(7):642-50.

10. Ray-Coquard I, Ovarian tumors of sex cord-stromal origin. Orphanet Encyclopedia. 2004.

11. Tisne L, Barzelatto J, Stevenson C. Study of thyroid function during pregnancy-puerperal state with radioactive iodine. Bol Soc Chil Obstet Ginecol. 1955;20:246-51. [in Spanish]

12. ACOG. Practice bulletin \#53: diagnosis and treatment of gestational trophoblastic disease. Obstet Gynecol. 2004;103(6):1365-77.

13. Hoskins WJ, Perez CA, Young RC. Principles and practice of gynecologic oncology. Philadelphia: Lippincott; 1992.

Ready to submit your research? Choose BMC and benefit from:

- fast, convenient online submission

- thorough peer review by experienced researchers in your field

- rapid publication on acceptance

- support for research data, including large and complex data types

- gold Open Access which fosters wider collaboration and increased citations

- maximum visibility for your research: over $100 \mathrm{M}$ website views per year

At $\mathrm{BMC}$, research is always in progress.

Learn more biomedcentral.com/submissions 